\title{
A New Perspective to Measuring Employee Growth: Developing a Successful Aging at Work Scale
}

\author{
Stanimira K. Taneva \\ University of Nottingham \\ Georgi P. Yankov \\ Development Dimensions International (DDI)
}

Follow this and additional works at: https://scholarworks.bgsu.edu/pad

Part of the Developmental Psychology Commons, Industrial and Organizational Psychology

Commons, Organizational Behavior and Theory Commons, Organization Development Commons, Quantitative Psychology Commons, and the Training and Development Commons

How does access to this work benefit you? Let us know!

\section{Recommended Citation}

Taneva, Stanimira K. and Yankov, Georgi P. (2020) "A New Perspective to Measuring Employee Growth: Developing a Successful Aging at Work Scale," Personnel Assessment and Decisions: Number 6 : Iss. 1 , Article 5.

DOI: https://doi.org/10.25035/pad.2020.01.005

Available at: https://scholarworks.bgsu.edu/pad/vol6/iss1/5

This Measurement and Measures is brought to you for free and open access by the Journals at ScholarWorks@BGSU. It has been accepted for inclusion in Personnel Assessment and Decisions by an authorized editor of ScholarWorks@BGSU. 


\title{
A New Perspective to Measuring Employee Growth: Developing a Successful Aging at WORK SCALE
}

\author{
Stanimira K. Taneva ${ }^{1}$ and Georgi P. Yankov ${ }^{2}$
}

1. University of Nottingham, UK

2. Development Dimensions International (DDI)

ABSTRACT

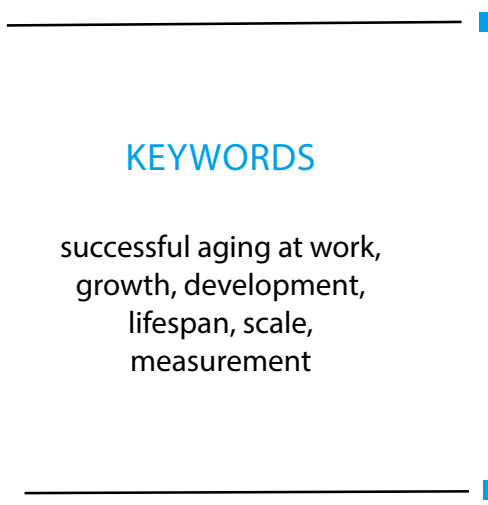

\begin{abstract}
The aging of the world's population has become a grand societal challenge, which requires an urgent response from researchers, professionals, and the wider society. One way to respond to this challenge is by supporting individuals in sustaining longer and healthier working lives, that is, age successfully. Although the advantages of promoting and enabling successful aging at work have been widely acknowledged, no single instrument for measuring this construct has been published so far. We develop and test in three consecutive samples a two-dimensional successful aging at work scale. This novel instrument is rooted conceptually in the most recent theoretical developments and is applicable to a variety of work settings and groups of workers. It can be used by both employees and employers for the purposes of individual and organizational development. We also propose directions for future research.
\end{abstract}

The emerging concept of successful aging at work (SAW) is rooted in the contemporary interpretations of the organizational and lifespan developmental theories. It emphasizes the important role of workplaces for successful aging (Olson \& Schultz, 2019), implying that long and positive work-related experiences can be sustained through successful adaptation to both intra-individual (e.g., age-related) and external (e.g., environmental) changes (Kooij, 2015; Olson \& Schultz, 2019; Zacher, 2015a). Kooij (2015) described SAW as the sustainable maintenance of an individual's work ability, health, and motivation across the working life cycle. In this definition, the active role of the employee for the creation of work resources and securing an ongoing person-environment fit is of key importance. Zacher $(2015 \mathrm{a}, \mathrm{b})$ pointed out that SAW is not limited to maintaining current levels of functioning and may refer to a worker's development or growth. Thus, SAW can be viewed as an intra-individual age-related trajectory to a work outcome (e.g., well-being or job performance) that deviates positively from the average age-related trajectory. Even an employee who has experienced a decline in a work outcome over time may be aging successfully at work when his/her trajectory is more positive than the average age-related trajectory (Zacher, 2015a, b).

In a systematic way, Zacher, Kooij, and Beier (2018) outlined the factors contributing to active aging at work (AAW), which is a construct that somewhat overlaps with
SAW (cf. Zacher, 2015a). AAW is described as workers' ability to "maintain or improve (1) their physical, mental, and social well-being; (2) continue to show high levels of work engagement and performance; and (3) experience fair treatment and employment security" in the aging process (Zacher et al., 2018, p. 37). Because development is a lifelong process, AAW refers to workers of all ages and career stages. Multilevel factors (individual, team, organizational, and wider societal) contribute to AAW/SAW (see also Kooij, Zacher, Wang, \& Heckhausen, 2019). The idea of understanding AAW/ SAW in relation to both internal (e.g., person) and external (e.g., environmental) factors is in line with the ongoing criticism that being focused mostly on the process of intra-individual development, lifespan theories overall are likely to neglect the effects of the context on the

\footnotetext{
Corresponding author:

Stanimira Taneva

University of Nottingham, Room B42, Law \& Social Sciences Building, University Park, Nottingham, NG7 2RD, United Kingdom

Email:Stanimira.Taneva@nottingham.ac.uk

This study follows a 2-year fellowship program ("THRIVING IN THE WORKPLACE - SUPPORTING PEOPLE AT THE AGE OF 55 YEARS AND OVER IN SATISFYING AND PRODUCTIVE WORK") funded by the European Commission under its Marie Curie Intra-European Fellowship scheme.
} 
individual's development (Olson \& Schultz, 2019).

Given the increasing interest in AAW/SAW from a contemporary lifespan perspective (Zacher et al., 2018), it is surprising that no measure of this construct has been developed yet. In two consecutive studies in 2006 and 2007, Robson and his colleagues conceptualized tentative criteria for successful aging in the workplace and developed an inventory for measuring them (Robson \& Hansson, 2007; Robson, Hansson, Abalos, \& Booth, 2006). Zacher \& Rudolph (2017) criticized this model for neglecting the contextual factors and work outcomes by focusing entirely on person factors (behavioral strategies). In addition, Zacher \& Rudolph (2017) concluded that because the behavioral strategies suggested by Robson et al. (Robson \& Hansson, 2007; Robson et al., 2006) do not interact with age, these strategies cannot be considered successful aging strategies. Most recently, Kooij and colleagues acknowledged the difficulty of operationalizing and, thus, measuring the construct SAW (Kooij et al., 2019).

As with Zacher (2015a), we understand SAW as a process of multidimensional intra-individual growth, which is age related, associated with various subjective and objective criteria, and may be facilitated (or constrained) by multilevel factors. Based on Zacher's (2015a) definition of SAW and the framework of AAW factors by Zacher et al. (2018), the purpose of our study is to extend the knowledge of SAW by: (a) operationalizing important facets of the construct SAW and (b) creating a single measure of SAW. We focus on the individual experiences and outcomes of SAW, as well as on both person and environmental antecedents of SAW in organizational context. We also consider the potential interactions of these factors with workers' age (cf. Zacher et al., 2015a, 2018). We test the psychometric properties of the new measure in three consecutive MTurk samples and suggest directions for future research.

\section{Operationalizing Successful Aging at Work}

Employees' experiences of SAW. The impacts of age-related changes on work behaviors and outcomes (especially in late career) are extensively documented. The nature and extent of age-related changes may vary significantly across individuals due to differences in person and environmental factors. These changes (e.g., in workers' cognitive abilities, personality, and motivation) are likely to reflect various developmental losses and gains across the working life cycle (Kanfer \& Ackerman, 2004; Warr, 2001). Recently, the number of studies focused on the positive (i.e., developmental gains) as opposed to loss-related (i.e., developmental declines) aspects of the aging process has increased. For example, in a qualitative study with 37 older workers (aged 55 years and over) from two countries (Bulgaria and United Kingdom) and two industrial sectors (healthcare and information and communication technologies), Taneva, Arnold and Nicolson (2016) found that late career workers are well aware of how age-related changes may affect their work life and outcomes. Importantly, workers associate some of these changes (e.g., increased knowledge and experience, enhanced social and emotional experience) with their personal and professional development and, ultimately, with improved work outcomes. Thus, workers' perceptions of positive age-related changes (developmental gains; cf. Kanfer \& Ackerman, 2004) are likely to indicate workers' experiences of SAW.

In Taneva et al.'s (2016) study, along with their perceptions of increased knowledge and experience, (older) workers communicated perceptions of other areas of personal and professional growth, among which increased self-awareness and confidence, improved social skills, emotion regulation, ability to solve complex problems, and general adaptation to contextual changes. These findings, extracted from workers' narratives, correspond with the outcomes of earlier research in the lifespan tradition (e.g., Carstensen et al., 2011; Kanfer \& Ackerman, 2004). We suggest that workers' conceptualizations of positive intra-individual changes may shape an important domain of the construct SAW.

Personal and organizational strategies for SAW. From a lifespan theory perspective, aging is a proactive process of adaptation, driven by self-regulation in the form of life management strategies that individuals apply in order to deal with age-related changes (e.g., loss, gain, and/ or reorganization of resources) in themselves as well as changes in their environment (Kanfer \& Ackerman, 2004). The selective optimization with compensation (SOC) model (Baltes \& Baltes, 1990) proposes that individuals are likely to use strategies that fall into three categories of self-regulation processes (selection, optimization, and compensation) in their attempts to adapt to both age-related changes and changes in their environment. These proactive behaviors become more important with increased age and can be particularly useful in the workplace. Starting with the pioneering work of Abraham and Hansson (1995), a plethora of studies has demonstrated the positive effects of SOC strategies on (older) workers' well-being and performance (e.g., Moghimi, Scheibe, \& Freund, 2019; Moghimi, Zacher, Shreible, \& Van Yperen, 2017). Thus, SOC strategies may be an effective mechanism for achieving SAW.

Combining the advantages of the job design and lifespan theories, Truxillo, Cadiz, Rineer, Zaniboni, and Fraccaroli, (2012) proposed potential age-related effects of three subgroups of job characteristics (task, knowledge, and social) on work engagement, job satisfaction, and job performance. For example, they suggested that due to intra-individual age-related changes, some job characteristics such as job autonomy, task significance, skill variety, and social support may be preferred by older (compared to younger) workers and, therefore, facilitate positive work outcomes particularly in late career. Among others, Zacher et al. (2018) 
emphasized the importance of job autonomy, social embeddedness, and sense of meaning for aging workers. Therefore, allowing opportunities for higher job autonomy, task significance, skill variety, and social support may foster SAW across the lifespan (see also Cadiz, Rineer, \& Truxillo, 2019).

Both formal (e.g., Strategic Human Resource Management) and informal (e.g., i-deals between employees and their supervisors) human resource management (HRM) approaches are shown to be important for supporting workers' well-being and performance (Bal, 2015; Kooij, Jansen, Dikkers, \& De Lange, 2014). Some formal HRM practices (also referred to as "age-friendly," cf. Zacher et al., 2018) are viewed as having desirable effects especially for older workers. Kooij et al. (2014) conceptualized four bundles of HRM practices for aging workers, and among these are maintenance and development practices. Taneva and Arnold (2018) reported that a specific combination between some maintenance and development HRM practices predicted experiences of high work well-being (thriving at work) and high job performance in a large sample of older workers in the United Kingdom. These practices, most valued by the older workers, refer to access to training, recognition and respect, meaningful assignments, feedback from the supervisor, flexible working, and opportunities to work longer. In addition, there is considerable evidence about the value of informal work arrangements and the role of supervisors in late career. For example, Bal (2015) concluded that "individualization of career arrangements will be increasingly important in the sustainability of contemporary careers" (Bal, 2015, p. 1). Based on this evidence, we suggest that workers' access to a combination of certain HRM practices with informal work agreements (i-deals) may be instrumental for achieving SAW in organizations.

\section{Outcomes of Successful Aging at Work}

Theoretically, SAW has been positively associated with various individual-level work outcomes, among which work motivation, job performance, health, and well-being (Zacher, 2015a). So far, only a few studies have provided empirical support for some of these associations. For example, Taneva and Arnold (2018) reported three pathways to SAW in organizations that demonstrate the role of personal (SOC) and organizational (HRM) strategies for achieving high job performance. Moreover, they found that employees' psychological well-being mediated the relationships of personal and organizational strategies with self-rated job performance (task proactivity, extra- and in-role performance). Therefore, workers' well-being is an important and, perhaps more direct (compared to job performance), outcome of SAW.

Thriving at work is described as "the joint sense of vitality and learning, which communicates a sense of progress or forward movement in one's self-development" (Spreitzer,
Sutcliffe, Dutton, Sonenshein, \& Grant, 2005, p. 538). Experiences of thriving at work can be driven by both person and organizational factors (Spreizer, Porath, \& Gibson, 2012). Thriving at work is positively related to outcomes such as high job and career role performance, positive work behaviors, work-related, and overall well-being (Porath, Spreitzer, Gibson, \& Garnett, 2012). Two studies by Taneva and colleagues (Taneva et al., 2016; Taneva \& Arnold, 2018) demonstrated that high levels of thriving at work are also common among older workers. Hence, experiences of thriving at work can happen at all career stages. Moreover, thriving at work can be viewed as both a form of psychological well-being (cf. Spreitzer et al., 2005; Warr, 2007) and a criterion for SAW (Taneva \& Arnold, 2018).

As opposed to thriving, the emerging construct of surviving at work is described as the individual's tendency to preserve one's mental and physical resources by limiting one's work activities and perspectives to cope with work conditions that are perceived as highly demanding (Taneva et al., 2016). Such a preservation experience may indicate reduced levels or lack of SAW. However, Taneva and Arnold (2018) discovered that, at least in some circumstances, experiences of surviving at work may be indeed a sign of sustained person-environment fit and, ultimately, of SAW. This is also in line with Kooij's definition of SAW as sustainable maintenance (Kooij, 2015) and the definition of AAW by Zacker and colleagues (Zacher et al., 2018). Hence, surviving at work may be another indicator of SAW.

Furthermore, as outlined in the previous sections, individuals' experiences of SAW can be enhanced using personal (e.g., SOC) or organizational (e.g., HRM, i-deals, and job design) strategies that facilitate the regulation of one's resources. The concept of work ability (WA) describes the balance (fit) between work and personal resources (Tuomi, Ilmarinen, Jahkola, Katajarinne, \& Tulkki, 1998). Recent lifespan research has demonstrated that certain work (e.g., job control, feedback, and social support) and person (e.g., proactive behaviors) characteristics can support the maintenance and even the increase of WA, especially in late career (e.g., Weigl, Müller, Hornung, Zacher, \& Angerer, 2013). In this context, it has been suggested that WA may be a useful criterion for SAW in late career (and beyond) (Kooij, 2015; Weigl et al., 2013).

\section{METHOD}

\section{Participants}

We used three consecutive samples of overall 417 MTurk workers based in the United States (see Table 1) to pilot and validate our projected scale. We screened all responses for inattention with an instructive item ("Please, respond to this item with strongly disagree") and for speediness by requiring that respondents spent a minimum time of four seconds times the number of items in their survey. 
In line with previous theoretical conceptualizations that SAW refers to workers of all ages and career stages (cf. Zacher et al., 2018), we suggest that SAW can be explored and validated as a construct with workers at all career stages. However, for this study using MTurk samples, we set the minimal age for participation to 30 , anticipating that workers with longer work experience would be more likely to provide valid responses regarding their perceptions of SAW. In our pilot and calibration samples we strived to collect equal numbers of respondents in the age groups of 30-49 years and 50 years and over, so that we could explore potential differences between mid- and late-career groups.

\section{Measures}

We used adapted versions of six established measures: SOC strategies (Freund \& Baltes, 2002), five subscales from the Work Design Questionnaire (Morgeson \& Humphrey, 2006), Age-friendly HR practices (Taneva \& Arnold, 2018), Thriving at Work (Porath et al., 2012), Surviving at Work (Taneva \& Arnold, 2018), and the Work Ability Index (Tuomi et al., 1998). The first three measures refer to constructs similar to aspects of SAW as operationalized in the current paper and were used for evaluating the convergent validity of the new instrument. The last three measures are associated with outcomes of SAW and served for evaluating the SAW scale's criterion-related validity. Table 2 provides

\section{TABLE 1.}

Demographic Characteristics of Collected Samples

\begin{tabular}{lccc}
\hline \multirow{2}{*}{ Sample characteristics } & \multicolumn{2}{c}{ Samples } \\
\cline { 2 - 4 } & Prepilot & Pilot & Calibration \\
\hline Number of administered items & 58 & 67 & 45 \\
Initial sample size & 80 & 263 & 188 \\
Sample size after cleaning & 68 & 223 & 126 \\
Age & $58(S D=6.0)$ & $44.7(S D=11.5)$ & $46.1(S D=11.1)$ \\
Percent female & $59 \%$ & $58 \%$ & $45 \%$ \\
Percent White & $79 \%$ & $81 \%$ & $86 \%$ \\
Tenure at current organization & - & $8.3(S D=6.5)$ & $9.8(S D=8.0)$ \\
\hline
\end{tabular}

TABLE 2.

Validation Scales

\begin{tabular}{|c|c|c|c|c|}
\hline Measure & Authors & Variables & No. Items & Rating scale \\
\hline Thriving at Work & $\begin{array}{l}\text { Porath, Spreitzer, } \\
\text { Gibson \& Garnett } \\
\text { (2012) }\end{array}$ & $\begin{array}{l}\text { Thriving at work (energy and } \\
\text { learning) }\end{array}$ & 10 & $\begin{array}{l}\text { 7-pt. strongly disagree to } \\
\text { strongly agree }\end{array}$ \\
\hline Surviving at Work & $\begin{array}{l}\text { Taneva \& Arnold } \\
\text { (2018) }\end{array}$ & Surviving at work & 3 & $\begin{array}{l}\text { 5-pt. strongly disagree to } \\
\text { strongly agree }\end{array}$ \\
\hline $\begin{array}{l}\text { Age-Friendly HR } \\
\text { Practices }\end{array}$ & $\begin{array}{l}\text { Taneva \& Arnold } \\
\text { (2018) }\end{array}$ & Age-friendly practices (set of eight) & 8 & $\begin{array}{l}\text { 5-pt. strongly disagree to } \\
\text { strongly agree }\end{array}$ \\
\hline SOC Strategies & $\begin{array}{l}\text { Freund \& Baltes } \\
(2002)\end{array}$ & $\begin{array}{l}\text { Selection, optimization and } \\
\text { compensation strategies }\end{array}$ & 12 & 4-pt. a little to exactly \\
\hline Work Ability Index & Tuomi et al. (1998) & Work ability & 1 & $\begin{array}{l}10 \text {-pt. completely unable to } \\
\text { work to overall capacity at its } \\
\text { best }\end{array}$ \\
\hline $\begin{array}{l}\text { The Work Design } \\
\text { Questionnaire } \\
\text { (subscales) }\end{array}$ & $\begin{array}{l}\text { Morgeson \& } \\
\text { Humphrey (2006) }\end{array}$ & $\begin{array}{l}\text { Autonomy, task significance, skill } \\
\text { variety, social support, feedback from } \\
\text { others }\end{array}$ & 14 & $\begin{array}{l}\text { 5-pt. strongly disagree to } \\
\text { strongly agree }\end{array}$ \\
\hline
\end{tabular}


more information on these measures. We also collected data about participants' chronological age, gender, and organizational tenure via single items for each of these variables.

\section{Procedure}

Guided by Boateng, Neilands, Fronillo, Melgar-Quinonez, and Young's (2018) recommendations of best practices for scale development and validation, we worked through three main phases: item development, scale development, and scale evaluation. We outline the item development in this section, and in the Results section we outline the scale development and evaluation.

Item development. In line with the discussion in the previous sections of this paper, we identified three primary domains of the construct SAW: (a) experiences (of SAW), (b) personal, and (c) organizational strategies (for SAW). We used a combination of deductive and inductive approaches to generate an initial pool of 58 items. Most of the items were based on a review of the recently published lifespan literature on SAW. Where possible, we focused especially on the results of qualitative studies with older workers (e.g., Taneva et al., 2016). Workers' own interpretations of SAW are perhaps the best example of how SAW is understood and communicated in nonacademic terms. Hence, they can be a valuable source of items for measuring this construct and a prerequisite of high content validity.

In 2018, we used the online surveying platform Qualtrics to collect three samples of Mturk respondents: a prepilot, pilot, and calibration sample. Because in the literature published up-to date the construct SAW is most often associated with older workers (e.g., Robson et al., 2006; 2007), in our prepilot sample we included only participants aged 50 years and over. In the pre-pilot sample, we included the initially developed 58 items and the validation scales (Table 2). Based on reliability coefficients (alphas of Cronbach), item-total correlations (ITCs), and item-level correlations with the validation scales, we found preliminary support for the three conceptual domains.

To further evaluate the content validity of the initial item pool, we consulted an external expert on lifespan development and SAW. We provided the expert with operational definitions of each domain and asked him/her to evaluate each item from the initial pool with regard to its relevance to the domains. We compared the results of the expert evaluation with our own version. The two versions largely overlapped, and there were also suggestions for additional items. Considering the expert's recommendations, we added nine items to the initial pool, thus bringing it up to 67 items (Table 3).

We used the 67 items for all subsequent analyses. In the pilot study we administered the items and explored each item's ITC with its suggested subscale. For the calibration sample we conducted series of exploratory factor analyses (EFA) with principal-axis factoring and Oblimin rotation.
We used parallel analyses (Horn, 1965), and Velicer's (1976) very simple solution (VSS) criterion to determine the number of latent factors to extract. This is because Cattell's (1966) scree test and the eigenvalue greater than 1 rule are less reliable criteria (Ruscio \& Roche, 2012). We did this for each subscale separately, dropped items to make the subscales unidimensional, and then did an EFA across all retained items. All analyses were conducted with the packages psych (Revelle, 2019) and paran (Dinno \& Dinno, 2018) in an R programming environment.

After establishing the reliability of the scale, we provided proof of its construct validity via relationships with established scales measuring similar constructs (convergent validity) and group comparisons (differentiation of known groups; cf. Boateng et al., 2018). We also evaluated the instrument's criterion-related validity with respect to three outcomes of SAW.

\section{RESULTS}

\section{Scale Development}

Based on the pilot data, we eliminated items with low ITCs, as well as items with duplicating content (columns ICC and Decision in Table 4). This brought the 67 items to 45. Both parallel analyses and the VSS criterion indicated 2, 1, and 2 factors to extract from Experiences, Personal, and Organizational Strategies. We had to remove three items loading strongly or negatively on the secondary extracted factors (items 5 and 29 from Experiences, and item 53 from Organizational Strategies) to eliminate these redundant factors. The Loadings 1 columns in Table 4 presents the pattern matrix loadings before removing the items, whereas the Loadings 2 columns after the removal. Then, another round of parallel and VSS analyses confirmed both subscales' unidimensionality.

When the three subscales were entered simultaneously (columns Loadings 3), the Personal Strategies items loaded mostly on the same factor as the Experiences items. Based on Personal Strategies' mixed pattern loadings, we dropped the Personal Strategies subscale and pursued only the Experiences and Organizational Strategies (which we renamed to Strategies) subscales. We conducted an EFA only on Experiences and Strategies (Loadings 4) and removed items (column Final Decision in Table 4) that loaded strongly on the wrong factor (items 8 and 64), had low loadings (items 1, 16, and 54), cross-loaded (item 52), or repeated an item with better psychometric properties (items 11, 12, $18,19,47$, and 67). Item 7 cross-loaded but we kept it because of content validity concerns, whereas items 2 and 25 had somewhat lower loadings and low secondary factor loadings, but we also kept them for the same reason. The columns Final Loadings present the final pattern matrix of the Experiences and (Organizational) Strategies scales. This final solution indicated that Experiences explained 22\% and 
TABLE 3. List of Developed Items

\section{Experiences subscale}

1. My professional knowledge has improved significantly over time.*

2. I feel confident at work because of my increased knowledge and experience.*

3. I feel that my work-related knowledge and experience are not up to date (R).

4. Compared to the past, I feel that I can better manage my relationships with coworkers.*

5. Working in a team/with other people has become more important to me than it was before.*

6. I feel less confident than before in my ability to face work-related changes (R).

7. I feel more confident than before to raise an issue with my supervisor, when needed.*

8. I feel more confident than before to express my opinion at work openly.*

9. I can manage better than before complex issues at work.*

10. I feel less confident than before in my ability to respond to work demands (R).

11. Over the time I learnt how to better manage a complex work situation.*

12. I feel that my relationships with coworkers are meaningful.*

13. I feel that now I can build more meaningful relationships with coworkers than before.*

14. Having interesting and meaningful work assignments has become more important to me than before.

15. Compared to the past, I find it easier to deal with work conflicts.*

16. Helping colleagues at work is important to me.*

17. My experience has taught me to take things at work more lightheartedly than before.

18. Now, I feel more relaxed at work now than I did before.*

19. Now, I feel calmer when I face challenges at work than I did before.*

20. Now, I feel less emotional than before in the face of work challenges.

21. I feel increasingly worried, when facing work challenges (R).

22. Compared to the past, I find it easier to stay composed and focus on solving a challenging work situation.*

23. Now, I feel less calm than before when I face a challenging work situation (R).

24. Now, I appear to be more calm and optimistic when I face work challenges than I was before.*

25. I am confident that $I$ can easily adapt to changes in my work.*

26. Now, I am more aware of my strengths and how to better use them at work, than I was before.*

27. I think that my overall capacity to do my work has declined over the years (R).

28. I feel that my capacity to do my work has increased in time.

29. I am not so much worried if I lack some work skills, because I know how to make the best of the skills I have.*

\section{Personal strategies subscale}

30. Compared to before, I am better at choosing which goals are important to follow at work.*

31. When needed, I feel comfortable changing my goals at work.*

32. I prioritize work goals that are emotionally meaningful to me.*

33. I always do my best to achieve a work goal.*

34. I know how to organize my time for working on the most important goals.*

35. If a goal demands too much effort, I'd rather change my priorities (R). 


\section{TABLE 3. (CONT.)}

36. I am actively looking to learn new skills that will help me achieve my goals.*

37. I have learned to split my work better between myself and my coworkers.*

38. Now I need to put more effort in completing the same tasks as before.

39. Now I try to use technologies and tools that will make my work easier.

40. When needed, I change parts of my job, so that I can use my skills best.*

41. Sometimes, if I can't change my work tasks, I try to change the way I think about them.*

42. If I feel that my work is too difficult, I try to change the way the work is done.

43. I do not have enough opportunities to change the way I do my work. (R)

\section{Organizational strategies subscale}

44. When I need to, I can take additional or unpaid leave.

45. I have access to suitable training for updating my work skills.*

46. I feel that I don't have good enough opportunities for learning new skills at work (R).

47. My organization encourages me to never stop learning.*

48. My organization provides me with opportunities to keep my work skills up to date.*

49. I feel recognized and respected at work.*

50. I feel confident that I can stay with this organization for as long as I'd like.*

51. I have a lot of flexibility at work.*

52. I often work on challenging and meaningful tasks.*

53. My work has significance for society and the life of others.*

54. My work involves learning new things.*

55. My work does not involve much variety $(R)$.

56. I can always rely on prompt and helpful feedback from my supervisor.*

57. My supervisor helps me to improve my work.

58. I am free to decide how to do my job.*

59. I don't have the freedom to do my work as I desire (R).

60. I have a great deal of autonomy at work.

61. My work involves meeting and getting to know a lot of people.

62. I get support and understanding from my coworkers.

63. I get support and understanding from my supervisor.*

64. My work team is one of the best things about my job.*

65. My organization is open to negotiating personalized work arrangements with employees.*

66. In my organization, supervisors are flexible with the needs of their employees.*

67. If necessary, I can negotiate with my supervisor special work arrangements that fit my skills and circumstances.*

Note. Items with asterisks $(*)$ included in the calibration sample, items in bold retained in the final version of the scale.

Strategies $26 \%$ of the total variance, and the two latent factors correlated at $.66(p<.01)$.

\section{Scale Evaluation}

Table 5 presents the descriptive statistics and intercor- relations of the Experiences and Strategies subscales, the demographic variables, and the validation measures used for establishing our scale's construct (convergent) and criterion-related (concurrent) validity.

The correlations of SAW's total score with the HRM 


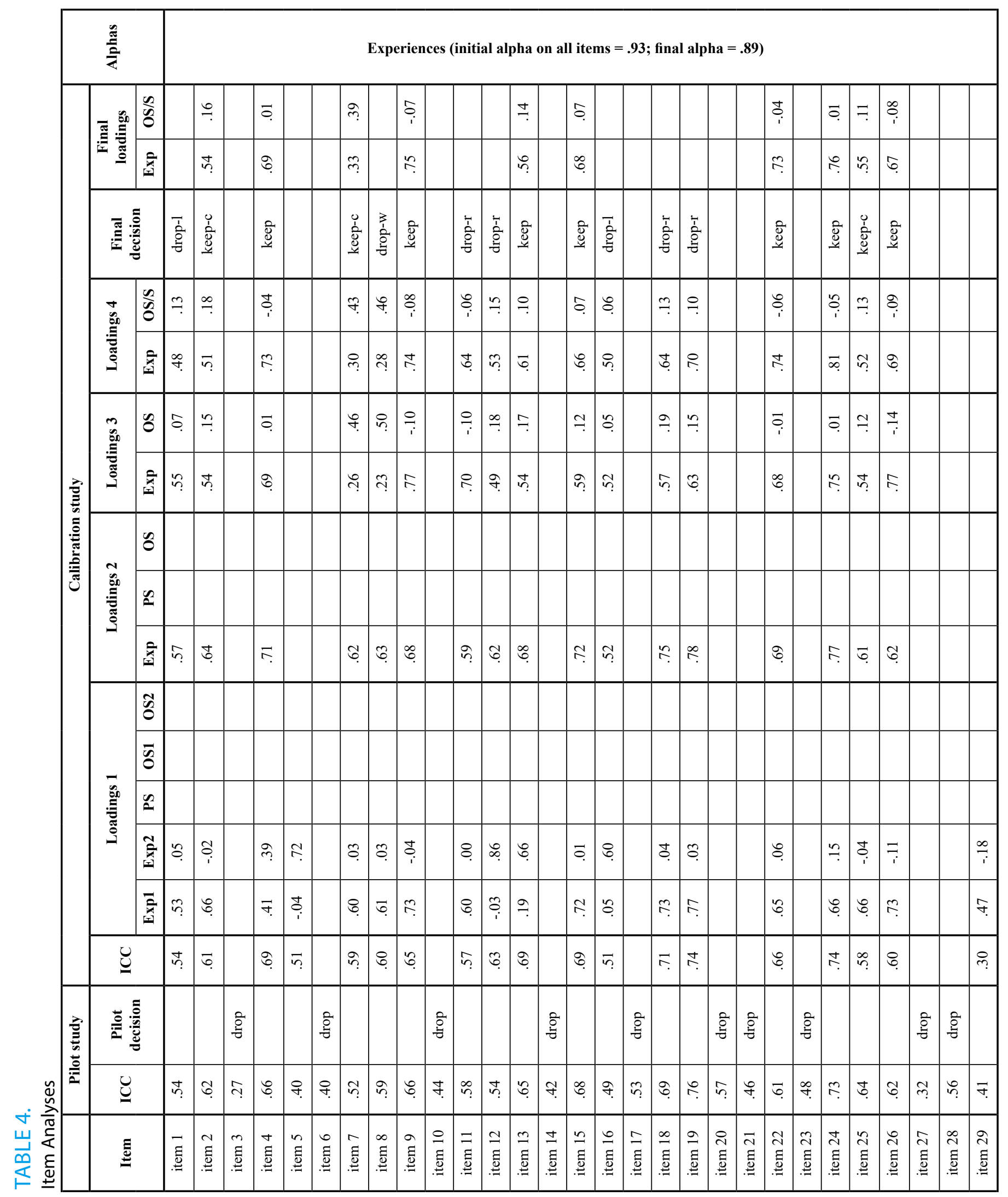




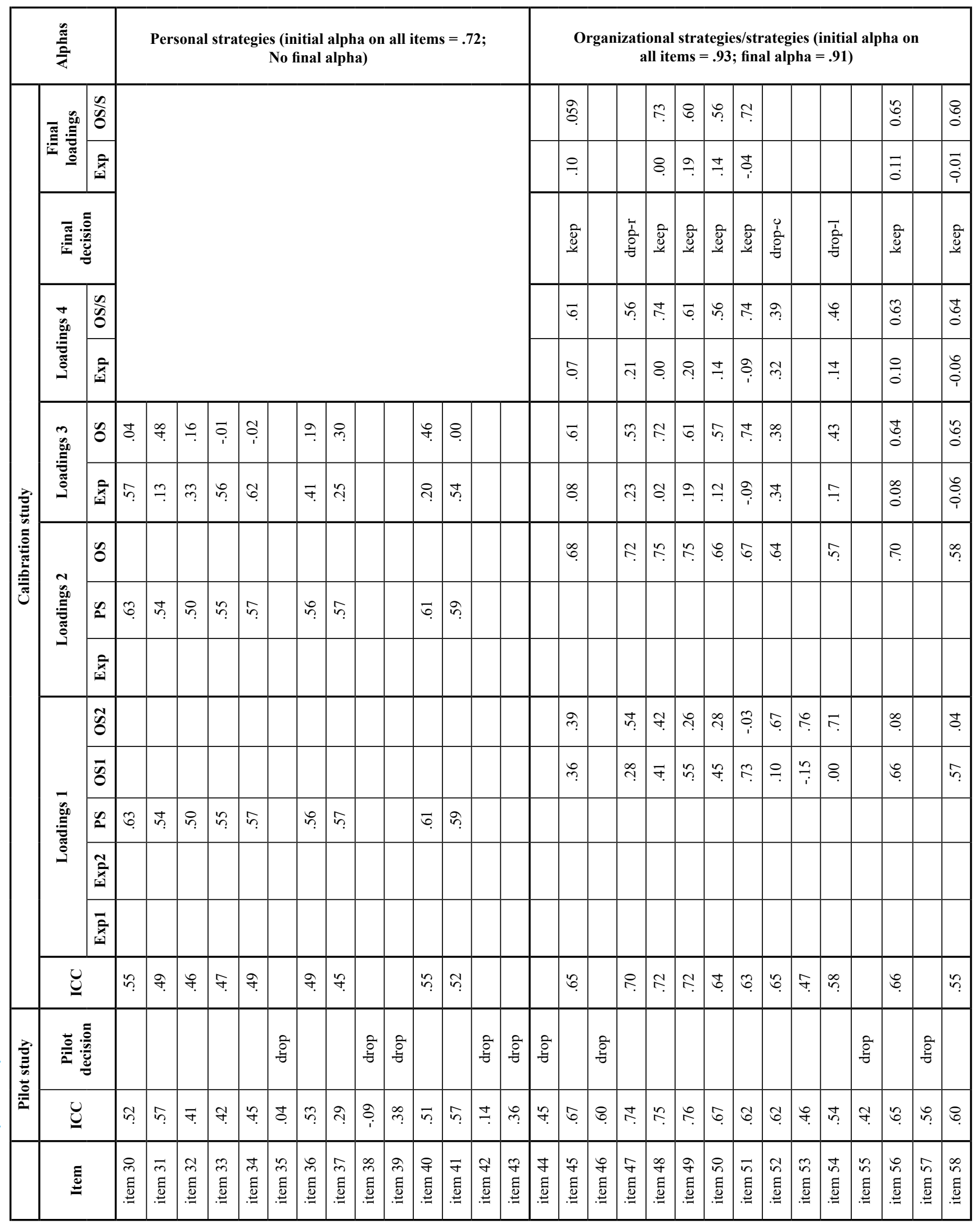




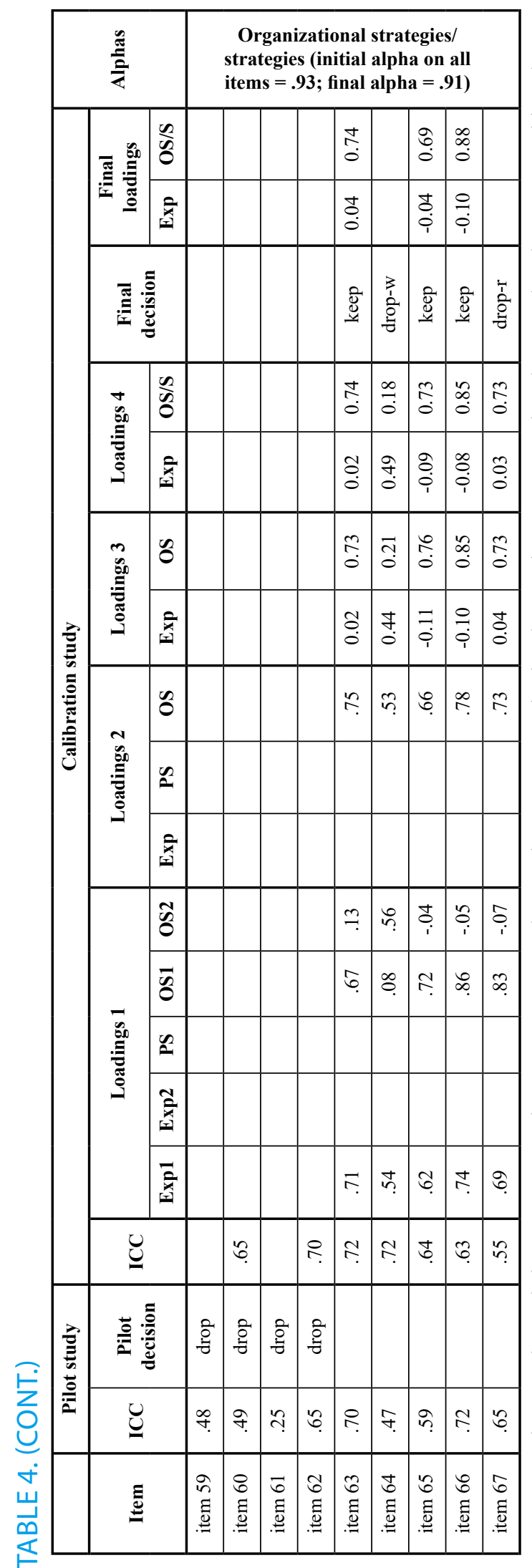

practices, the four SOC strategies, and the five job characteristics subscales were significant and of moderate (e.g., Task Significance, Skill Variety) to strong size (e.g., HRM practices, SOC, Autonomy). These positive relationships support the convergent validity of the SAW scale.

Regarding the differentiation of known groups (another aspect of construct validity), we tested for differences by age, gender, and organizational tenure. Two independent samples $t$-tests for age split into categories of 30-49 and above 50 years of age did not result in significant effects for Experiences $(t(347)=-1.00, p=.32)$ or Strategies $(t(347)$ $=-.89, p=.38)$. In addition, series of independent samples $t$-tests uncovered no significant gender differences in both subscales and the validation scales. Last but not least, in Table 5 organizational tenure relates significantly only to age, indicating that the older (compared to younger) employees have longer organizational tenure. The lack of significant relationship of organizational tenure with SAW shows that organizational tenure might not relate to SAW and its nomological network of constructs.

Finally, our scale correlated positively with the Thriving at Work and WA scales, which provides criterion validity evidence. However, the other scale, which we interpret as a criterion for SAW-Surviving at Work — did not relate significantly to the SAW scale score.

\section{DISCUSSION}

We developed and established the psychometric properties of the first single measure for SAW in the contemporary meaning of this construct (cf. Zacher, 2015a). We view SAW as a developmental process that may occur at all career stages and can be captured through individual-level outcomes such as improved WA and well-being. We operationalized the construct SAW through two clusters of employees' perceptions: (a) individuals' psychological experiences of age-related growth in the workplace (SAW), and (b) Strategies for achieving SAW. Experiences of growth may refer to various areas of perceived age-related positive changes, among which are improved knowledge and experience, social skills, emotion regulation, and adaptability in work-related situations (cf. Taneva et al., 2016). Strategies (or facilitators) for SAW may include both employee (e.g., proactive self-regulation) and organizational (e.g., job design, formal HRM and informal work arrangements) behaviors (cf. Bal, 2015; Baltes \& Baltes, 1990; Kooij et al., 2014; Taneva et al., 2016; Truxillo et al., 2012).

Subsequent empirical analysis with data from three consecutive MTurk samples with overall 417 workers in organizational setting revealed that the employees' experiences of SAW largely overlapped with the employees' percep- 


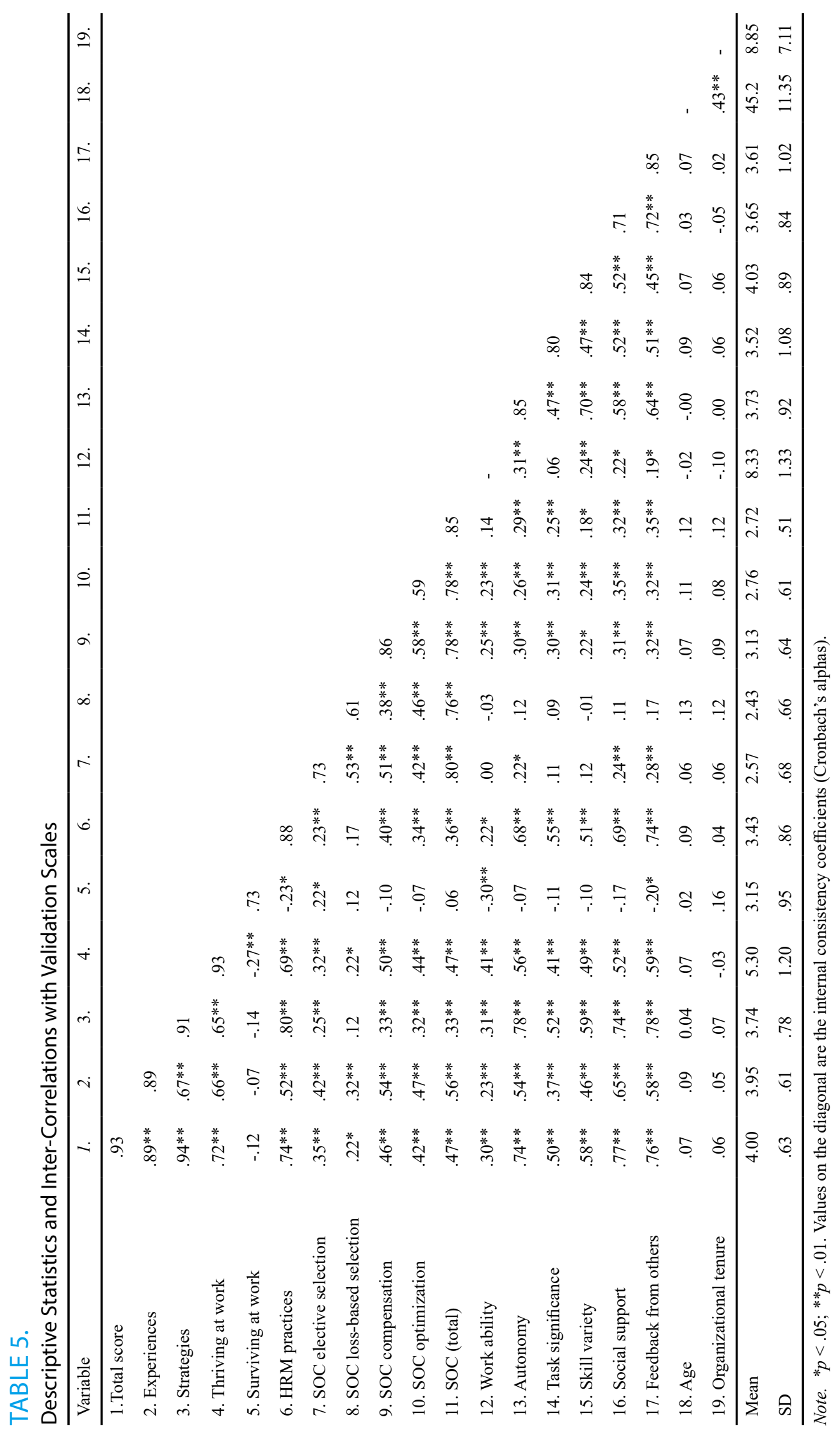


tions of individual-level facilitators of SAW (i.e., personal strategies). A potential explanation may be that SAW could be also described as a process of active self-regulation, driven by the individual's motivation to pursue person-environment fit (Kooij et al., 2019). Thus, the employees' perceptions of both positive age-related changes and proactive self-regulating behaviors (personal strategies) may reflect the construct SAW in the sense of perceived age-related growth (cf. Taneva et al., 2016).

Furthermore, we examined the construct and criterion-related validity of the new scale by exploring the associations of the SAW scale's total score with the scores of six established measures of personal (SOC) and organizational (job design, formal HRM) strategies, as well as subjective criteria for SAW (WA, thriving and surviving at work). The empirical analyses confirmed all anticipated relationships, apart from the association between the SAW score and the Surviving at Work score, which appeared to be lacking statistical significance. This may be because we suggested surviving at work as a tentative criterion for SAW. Although employees' experiences of surviving at work may indicate maintenance of resources and thus sustained work outcomes (e.g., well-being) (cf. Kooij, 2015; Taneva \& Arnold, 2018), the construct surviving at work does not imply perceived growth as it is the case with SAW in Zacher's definition (cf. Zacher, 2015a).

\section{Contributions to Theory and Practice}

This study contributed to theory development in several ways. First, it systemized and further conceptualized key domains of the emerging construct SAW by linking person and environmental variables. Thus, it responded to recent calls for integrating multilevel factors when examining this construct (cf. Zacher, 2015a; Zacher et al., 2018). Second, it focused on the synergies between these domains and gained new insights into how they operate together, as well as separately. Third, it translated into practical terms each domain and explored its construct and criterion-related validity with regard to other, well-known constructs and demographic variables. Thus, new information about the content of each domain was found and a new measurement instrument was developed. From a practitioner point of view, this instrument will help training and development professionals to capture workers' experiences and potential to age successfully in organizations. Moreover, this scale may help workers in monitoring and directing their own experiences of SAW. This, in turn, may inform organizational systems and initiatives aiming at supporting SAW and therefore ensure employees' higher work well-being and performance. In the longer term, supporting SAW from both individual and organizational perspectives may help in sustaining longer and healthier working lives.

\section{Limitations and Avenues for Future Research}

Future research needs to provide further evidence of the validity of the SAW scale. For example, we found a significant positive relationship of age with organizational tenure, but we did not find evidence of age-related differences regarding the employees' self-perceptions of SAW. The lack of evidence of age-related differences may be because the age characteristics of our participant groups were not specified well enough or because generally there is no clear, definitive criterion for dividing workers into "older" and "younger" (cf. Zaniboni, Kmicinska, Truxillo, Kahn, Paladino, \& Fraccaroli, 2019). Also, our pilot and calibration samples did not include any participants of over 60 years of age. It may be the case that people aged 60 years and over, who stay in the workforce, experience SAW differently compared to workers at younger ages. Future research should address this issue. In addition, it is possible that various moderators play a role in workers' aging (cf. Felicitas, Goecke, \& Kunze, 2016; Zacher et al., 2018). Importantly, the lack of evidence of age-related differences in the employees' self-perceptions of SAW may indicate that the measure, which we suggest, captures SAW at all career stages (cf. Zacher et al., 2018).

Furthermore, at this stage of the scale's development we focused on several job characteristics and a small range of demographic variables. We did not collect information about those work characteristics, which may be negatively associated with SAW at some career stages (e.g., high physical demands in late career), the participants' occupations, organizations, and industrial sectors. Such information would help contextualizing and understanding better the SAW construct and measure. Also, we relied on data from MTurk workers, which may limit the generalizability of the study results (cf. Walters, Christakis, \& Wright, 2018). In the future, SAW researchers should seek to collect data from workers at all career stages and various occupational/ industrial/cultural settings with non-MTurk samples. This will allow comparisons between groups of workers at different career stages/occupations/sectors/cultures. To better understand the age dimension of SAW, investigators should consider other age constructs (e.g., subjective age) in addition to workers' chronological age (cf. Felicitas et al., 2016) and follow a longitudinal approach (cf. Kooij et al., 2019). In addition, in this study we captured the associations between SAW and only three work-related outcomes (i.e., WA and psychological well-being, understood as both thriving at work and surviving at work), all of which self-rated. Data regarding other work outcomes (e.g., workers' performance, health, other forms of well-being, job attitudes, work motivation, expectations, etc.; cf. Zacher, 2015a) and from multiple sources will be most valuable in future research with the SAW scale. 


\section{REFERENCES}

Abraham, J. D., \& Hansson, R. O. (1995). Successful aging at work: an applied study of selection, optimization, and compensation through impression management. Journals of Gerontology, Series B: Psychological Sciences and Social Sciences, 50, 94-103. doi:10.1093/geronb/50B.2.P94

Bal, P. (2015). Sustainable careers: enabling older workers to continue working through individualized work arrangements. In A. De Vos and B. Van der Heijden, (Eds.), Handbook of research on sustainable careers (pp. 304-318). Cheltenham, UK: Edward Elgar.

Baltes, P. B., \& Baltes, M. M. (1990). Psychological perspectives on successful aging: The model of selective optimization with compensation. In P. B. Baltes \& M. M. Baltes. (Eds.), Successful aging: Perspectives from the behavioral sciences (pp. 1-34). New York, NY: Cambridge University Press. doi:10.1017/CBO9780511665684.003

Boateng, G. O., Nielands, T. B., Frongillo, E. A., Melgar-Quinonez, H. R., \& Young, S. L. (2018). Best practices for developing and validating scales for health, social, and behavioral research: A primer. Frontiers of Public Health, 6, 149, doi:10.3389/ fpubh.2018.00149

Cadiz, D. M., Rineer, J. R., \& Truxillo, D. M. (2019). Lifespan perspectives on job and work design. In B. B. Baltes, C. W. Rudolph, \& H. Zacher (Eds.), Work across the lifespan (pp. 263290). London, UK: Academic Press, Elsevier

Carstensen, L. L., Turan, B., Scheibe, S., Ram, N., Ersner-Hershfield, H., Samanez-Larkin, G. R.,...\& Nesselroade, J. R. (2011). Emotional experience improves with age: evidence based on over 10 years of experience sampling. Psychology and Aging, 26, 21-33. doi:10.1037/a0021285

Cattell, R. B. (1966). The scree test for the number of factors. Multivariate Behavioral Research, 1, 245-276. doi:10.1207/ s15327906mbr0102_10

Dinno, A., \& Dinno, M. A. (2018). Package "paran." Dortmund, Germany: R package version 1.5.2

Felicitas, T., Goecke, E., \& Kunze, F. (2016). The moderation role of subjective age in the chronological age/absenteeism relationship in teams. Academy of Management Proceedings, (1):12970. doi:10.1080/1359432X.2018.1485651

Freund, A. M., \& Baltes, P. B. (2002). Life-management strategies of selection, optimization and compensation: Measurement by self-report and construct validity. Journal of Personality and Social Psychology, 82(4), 642-662. doi:10.1037/00223514.82.4.642

Horn, J. L. (1965). A rationale and test for the number of factors in factor analysis. Psychometrika, 30, 179-185. doi:10.1007/ BF02289447

Kanfer, R., \& Ackerman, P. L. (2004). Aging, adult development, and work motivation. Academy of Management Review, 29(3), 440-458. doi:10.2307/20159053

Kooij, D. T. A. M. (2015). Successful aging at work: The active role of employees. Work, Aging and Retirement, 1(4), 309-319. doi:10.1093/workar/wav018

Kooij, D. T. A. M., Jansen, P. G. W., Dikkers, J. S. E., \& De Lange, A. H. (2014). Managing aging workers: a mixed methods study on bundles of HR practices for aging workers. The International Journal of Human Resource Management, 25(15), 21922212. doi:10.1080/09585192.2013.872169
Kooij, D. T. A. M., Zacher, H., Wang, M., \& Heckhausen, J. (2019). Successful aging at work: A process model to guide future research and practice. Industrial and Organizational Psychology: Perspectives on Science and Practice. Retrieved on 13.08.2019 from ResearchGate.

Moghimi, D., Scheibe, S., \& Freund, A. (2019). The model of selection, optimization, and compensation. In B. B. Baltes, C. W. Rudolph, \& H. Zacher (Eds.), Work across the lifespan (pp. 81 - 110). London, UK: Academic Press, Elsevier. eBook ISBN: 9780128127575

Moghimi, D., Zacher, H., Scheibe, S., \& Van Yperen, N. W. (2017). The selection, optimization, and compensation model in the work context: A systematic review and meta-analysis of two decades of research. Journal of Organizational Behavior, 38(2), 247-275. doi:10.1002/job.2108

Morgeson, F. P., \& Humphrey, S. E. (2006). The Work Design Questionnaire (WDQ): Developing and validating a comprehensive measure for assessing job design and the nature of work. Journal of Applied Psychology, 91, 1321-1339. doi:10.1037/0021-9010.91.6.1321

Olson, D., \& Shultz, K. (2019). Lifespan perspectives on successful aging at work. In B. B. Baltes, C. W. Rudolph, \& H. Zacher (Eds.), Work across the lifespan (pp. 215 - 234). London, UK: Academic Press, Elsevier. eBook ISBN: 9780128127575

Porath, C., Spreitzer, G., Gibson, C., \& Garnett, F. G. (2012). Thriving at work: Toward its measurement, construct validation, and theoretical refinement. Journal of Organizational Behavior, 33(2), 250-275. doi:10.1002/job.756

Revelle, W. (2019). psych: Procedures for personality and psychological research. Evanston, IL: Northwestern University, Evanston. $\mathrm{R}$ package version 1.8.12

Robson, S. M., \& Hansson, R. O. (2007). Strategic self-development for successful aging at work. International Journal of Aging and Human Development, 64(4), 331-359. doi:10.2190/Q303-171U-7686-8517

Robson, S. M., Hansson, R. O., Abalos, A., \& Booth, M. (2006). Successful aging: Criteria for aging well in the workplace. Journal of Career Development, 33(2), 156-177. doi:10.1177/0894845306292533

Ruscio, J., \& Roche, B. (2012). Determining the number of factors to retain in an exploratory factor analysis using comparison data of a known factorial structure. Psychological Assessment, 24(2), 282-292. doi:10.1037/a0025697

Spreitzer, G. M., Porath, C. L., \& Gibson, C. B. (2012). Toward human sustainability: How to enable more thriving at work. Organizational Dynamics, 41(2), 155-162. doi:10.1016/j.orgdyn.2012.01.009

Spreitzer, G. M., Sutcliffe, K. M., Dutton, J. Sonenshein, S., \& Grant, A. M. (2005). A socially embedded model of thriving at work. Organization Science, 16(5), 537-549. doi:10.1287/ orsc. 1050.0153

Taneva, S. K., \& Arnold, J. (2018). Thriving, surviving and performing in late career: A mixed-method study of pathways to successful aging in organizations. Work, Aging and Retirement, 4 (2), 189-212. doi:10.1093/workar/wax027

Taneva, S. K., Arnold, J., \& Nicolson, R. (2016). The experience of being an older worker in an organization: a qualitative analysis. Work, Aging and Retirement, 2(4), 396-414. doi: 10.1093/workar/waw011 
Truxillo, D. M., Cadiz, D. M., Rineer, J. R., Zaniboni, S., \& Fraccaroli, F. (2012). A lifespan perspective on job design: Fitting the job and the worker to promote job satisfaction, engagement, and performance. Organizational Psychology Review, 2(4), 340-360. doi: 10.1177/2041386612454043

Tuomi, K., Ilmarinen, J., Jahkola, A., Katajarinne, L., \& Tulkki, A. (1998). Work Ability Index 2nd Edition. Helsinki: Institute of Occupational Health.

Velicer, W. (1976). Determining the number of components from the matrix of partial correlations. Psychometrika, 41, 321327. doi:10.1007/BF02293557

Walters, K., Christakis, D. A., \& Wright, D. R. (2018). Are Mechanical Turk worker samples representative of health status and health behaviors in the U.S.? PloS one, 13(6), e0198835. doi:10.1371/journal.pone.0198835

Warr, P. (2001). Age and work behavior: Physical attributes, cognitive abilities, knowledge, personality traits and motives. In C. L. Cooper, \& I. T. Robertson (Eds.), International review of industrial and organizational psychology (pp. 1-36). New York, NY: Wiley.

Warr, P. (2007). Work, happiness, and unhappiness. Mahwah, NJ: Erlbaum. eBook ISBN 9780203936856.

Weigl, M., Müller, A., Hornung, S., Zacher, H., \& Angerer, P. (2013). The moderating effects of job control and selection, optimization, and compensation strategies on the age-work ability relationship. Journal of Organizational Behavior, 34(5), 607-628. doi:10.1002/job.1810

Zacher, H. (2015a). Successful aging at work. Work, Aging and Retirement, 1(1), 4-25. doi: 10.1093/workar/way002

Zacher, H. (2015b). The importance of a precise definition, comprehensive model, and critical discussion of successful aging at work. Work, Aging and Retirement, 1(4), 320-333. doi:10.1093/workar/wav020

Zacher, H., , Rudolph, W. (2017). Successful aging at work and beyond: A review and critical perspective. In S. Profili, A. Sammarra , L. Innocenti (Ed.) Age Diversity in the Workplace (Advanced Series in Management, Volume 17) (pp. 35 - 64). Bradford, UK: Emerald Publishing Limited. elSBN: 978-178743-073-0

Zacher, H., Kooij, D. T.A.M., \& Beier, M. E. (2018). Active aging at work: Contributing factors and implications for organizations. Organizational Dynamics, 47(1), 37-45. doi:10.1016/ j.orgdyn.2017.08.001

Zaniboni, S., Kmicinska, M., Truxillo, D. M., Kahn, K., Paladino M. P., \& Fraccaroli, F. (2019). Will you still hire me when I am over 50 ? The effects of implicit and explicit age stereotyping on resume evaluations, European Journal of Work and Organizational Psychology, 28:4, 453-467, doi:10.1080/135943 2X.2019.1600506

RECEIVED 05/02/19 ACCEPTED 11/05/19 